\title{
Variety of Bio-Hydrocarbon Precursors for the Synthesis of Carbon
}

\section{Nanotubes}

M.S. Azmina ${ }^{1 *}$, A.B. Suriani ${ }^{1}$, M. Salina ${ }^{2}$, A.A. Azira ${ }^{3}$, A.R. Dalila ${ }^{1}$, N.A Asli ${ }^{4}$, J. Rosly ${ }^{1}$, Roslan Md Nor ${ }^{5}$ and M. Rusop ${ }^{4}$

${ }^{1}$ Department of Physics, Faculty of Science and Mathematics, Universiti Pendidikan Sultan Idris, 35900 Tanjung Malim, Perak, Malaysia.

${ }^{2}$ Faculty of Engineering Universiti Industri Selangor,Bestari Jaya Campus, Jalan Timur Tambahan, 45600 Bestari Jaya, Selangor, Malaysia.

${ }^{3}$ Advanced Rubber Technology Unit, Technology \& Engineering Division, Malaysian Rubber Board, RRIM Research Station Sg. Buloh, 47000, Selangor, Malaysia.

${ }^{4}$ NANO-SciTech Center, Institute of Science, Universiti Teknologi MARA, 40450 Shah Alam, Selangor, Malaysia.

${ }^{5}$ Department of Physics, Faculty of Science, University of Malaya, 50603 Kuala Lumpur, Malaysia

*Corresponding author: absuriani@yahoo.com; Tel.: +60192117002; fax: +6054583616

Keywords: Nanotubes, Chemical vapor deposition, Scanning electron microscopy, Raman spectroscopy and catalytic decomposition of oils.

Abstract. In this work, we have synthesized carbon nanotubes (CNT) using different biohydrocarbon precursors namely palm, olive, coconut, corn and sesame oils. Prior to the synthesis process, thermogravimetric analysis (TGA) characterization was performed on the carbon precursors to facilitate the optimization procedures of CNT and reach maximum yield and higher quality CNT. The CNT arrays were deposited on a silicon substrate by thermal catalytic decomposition of the precursor using $5.33 \mathrm{wt} \%$ ferrocene. The synthesis was carried out at $750{ }^{\circ} \mathrm{C}$ for $60 \mathrm{~min}$ under argon ambient. The samples were characterized using field emission scanning electron microscopy, microRaman spectroscopy and TGA analysis. The difference in oil density resulted in different quality and 
tube diameter of CNT produced. Among all, the CNT synthesized from coconut oil can be considered as the best bio-hydrocarbon precursor for higher quality $\left(\mathrm{I}_{\mathrm{D}} / \mathrm{I}_{\mathrm{G}} \sim 0.62\right)$ and good purity $(81.95 \%)$ CNT.

\section{Introduction}

Over the past decades, carbon nanotube (CNT) has shown great potential for application in the field such as field electron emission [1], nanocomposite [2], biosensor and energy storage [3]. This is due to its excellent electrical and mechanical properties, small radius of curvature at the tips and high thermal and chemical stability $[4,5]$. Several methods have been reported for the synthesis of CNT which were arc discharge [6], laser ablation [7] and chemical vapor deposition (CVD) [8, 9] methods. Among all, CVD is the most economical method and is easily scalable for mass production of CNT. Most of the CNT has been synthesized from precursors that were based on fossil fuel such as methane, acetylene, benzene and xylene. These precursors are diminishing in several decades time. Moreover, the cost of these raw materials is expected to increase in the future. Therefore, it is necessary to look for alternative precursors. Recently, the use of bio-hydrocarbon precursor such as camphor oil [10, 11], turpentine oil [12-14], eucalyptus oil [15], palm oil [16-19], waste cooking palm oil [20], neem oil [21], castor oil [22] and coconut oil [23] have been reported. The main factors of utilizing plant based precursor as carbon source is its sustainable feature which acts as renewable and cheap raw materials for large-scale CNT production.

In this paper, we report the synthesis of the CNT from bio-hydrocarbon precursors namely palm, olive, coconut, corn, and sesame oils using thermal chemical vapor deposition (TCVD) method. The synthesis was done by catalytic decomposition of oil with the assistance of ferrocene catalyst. The vaporization temperatures of the oil samples were obtained from the thermogravimetric analysis (TGA). This temperature was important to simplify and facilitate the optimization procedures of CNT preparation. 


\section{Experimental}

A typical synthesis setup was carried out which was similar to previous reports $[16,17,19,24]$. Ferrocene of $5.33 \mathrm{wt} \%$ were mixed in bio-hydrocarbon precursor. The mixture was stirred for 30 min before $6 \mathrm{ml}$ of them was loaded into the first furnace. Argon gas was later purged into the furnace for $10 \mathrm{~min}$ to flush out contaminants and to provide an inert atmosphere. Prior to the CNT synthesis, vaporization temperature of each oil was obtained from the TGA (Fig.1). The vaporization temperatures were ranging between 391.4 and $450.5^{\circ} \mathrm{C}$ as tabulated in Table 1 . These were the setup temperature for the first furnace and the synthesis temperature in second furnace was fixed at $750{ }^{\circ} \mathrm{C}$ for $60 \mathrm{~min}$. The as-grown CNT were characterized by field emission scanning electron microscope (FESEM-JOEL JSM-7600F), micro-Raman spectroscopy (Horiba Jobin Yvon-DU420A-OE-325 instrument), TGA analysis (Perkin Elmer Pyris 1 TGA) and energy-dispersive X-ray (EDX) spectroscopy.

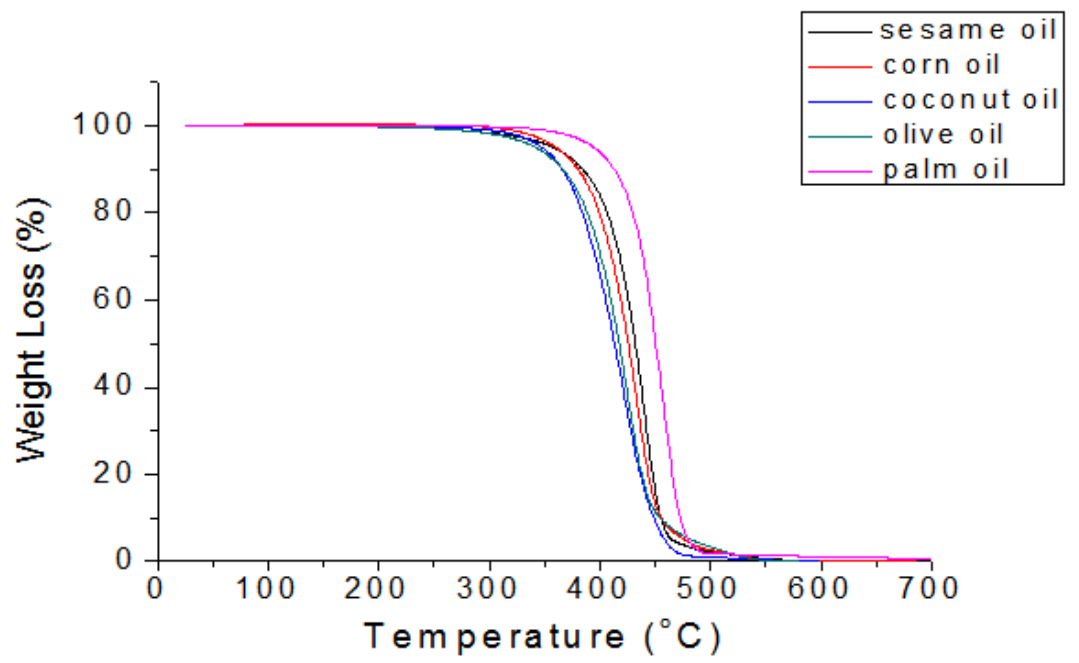

Fig. 1. TGA curves of bio-hydrocarbon precursors.

Table 1. Vaporization temperature for bio-hydrocarbon precursors.

\begin{tabular}{|c|c|}
\hline Bio-hydrocarbon Precursors & Vaporization Temperature $\left({ }^{\circ} \mathbf{C}\right)$ \\
\hline Palm oil & 450.5 \\
\hline Olive oil & 421.6 \\
\hline Coconut oil & 391.4 \\
\hline Corn oil & 433.2 \\
\hline Sesame oil & 441.5 \\
\hline
\end{tabular}




\section{Results and Discussions}

Fig. 2(a)-(j) show FESEM images of CNT synthesized from palm, olive, coconut, corn and sesame oils precursor respectively. From the FESEM observation, the productions of quasi-aligned CNT were seen in the samples synthesized from palm, coconut and olive oils, whereas the sesame and corn oils precursor produces non-aligned CNT. The CNT morphology was seen to be similar for all precursors except for the sample synthesized from sesame oil.

The sesame oil-CNT contains much more impurities such as amorphous carbon (a-C) and carbon particles. The sample also shows bigger tube diameter which was in the range of 125.0-141.0 $\mathrm{nm}$. The smallest and uniform diameters of the CNT were found from palm oil (25.2-36.5 nm) as a carbon precursor. This was followed with CNT synthesized from other precursors namely olive (35.6-37.5 nm), coconut (52.5-65.9 nm) and corn oils (60.0-67.6 nm). The surface morphology and nanotubes diameter of the CNT from bio-hydrocarbon were comparable to CNT from fossil fuel precursor (20.0-30.0 nm) [25-28]. In contrast to previous reports [23], the CNT synthesized from coconut oil in this study has a better surface morphology and tube diameters which [23] were found to be in the range of 80.0-100.0 $\mathrm{nm}$. However, a slight increase in CNT diameters (25.2-36.5 nm) were obtained from sample produced using palm oil precursor as compared to the previous study [17]. This was due to the substrates stacking configuration approach which were applied in the previous study [17]. But in this study the samplse were deposited on open configuration substrates. 

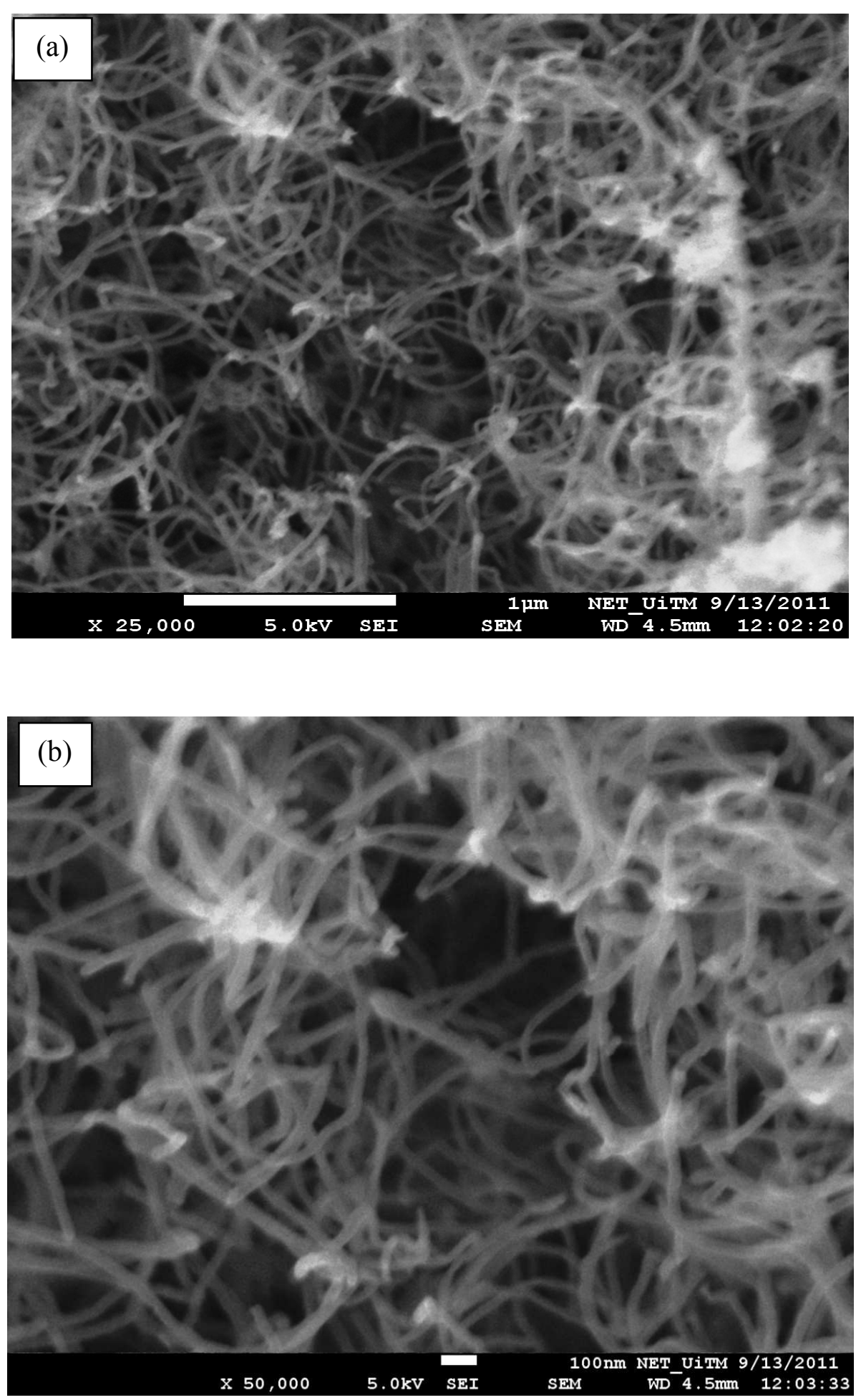

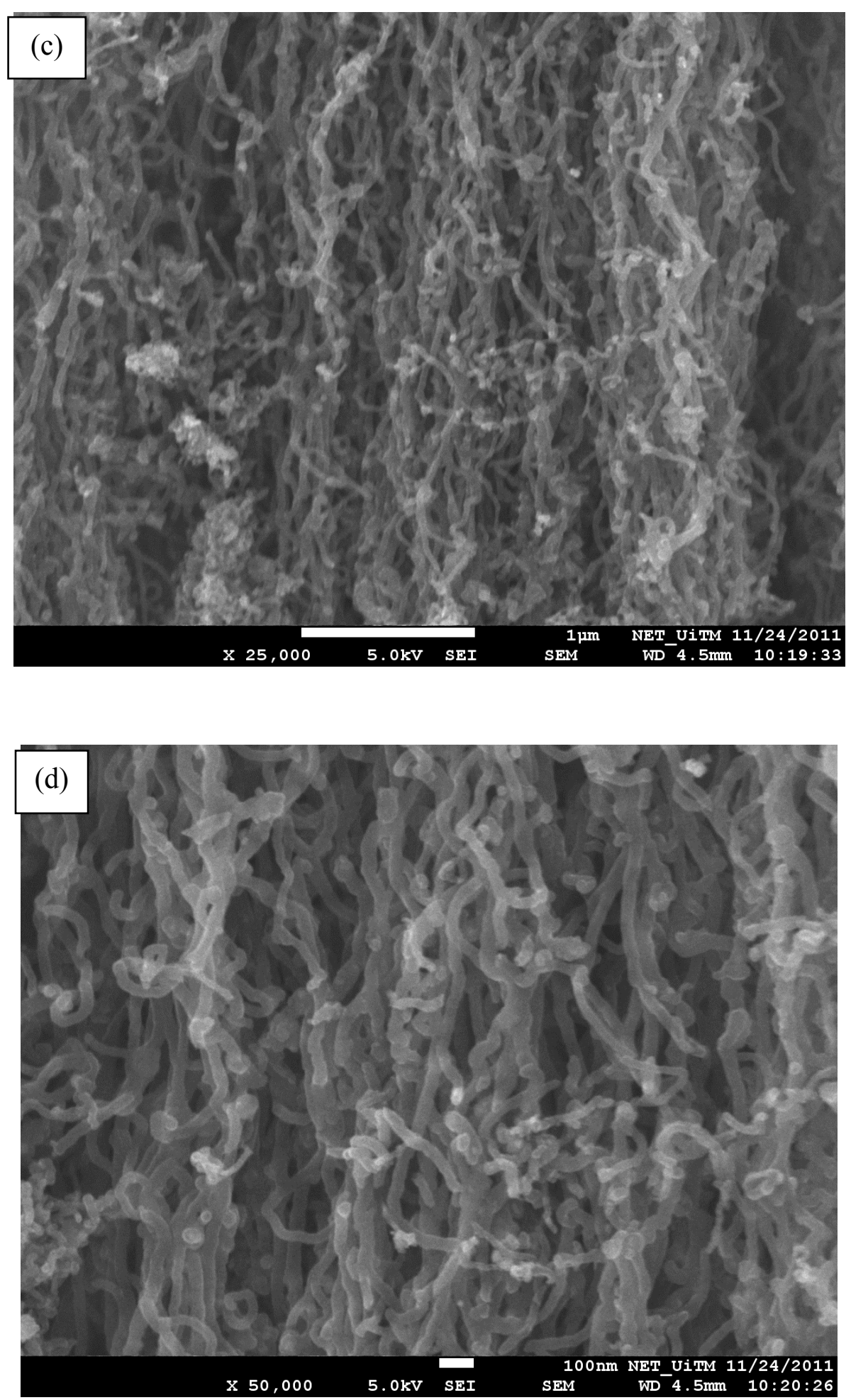

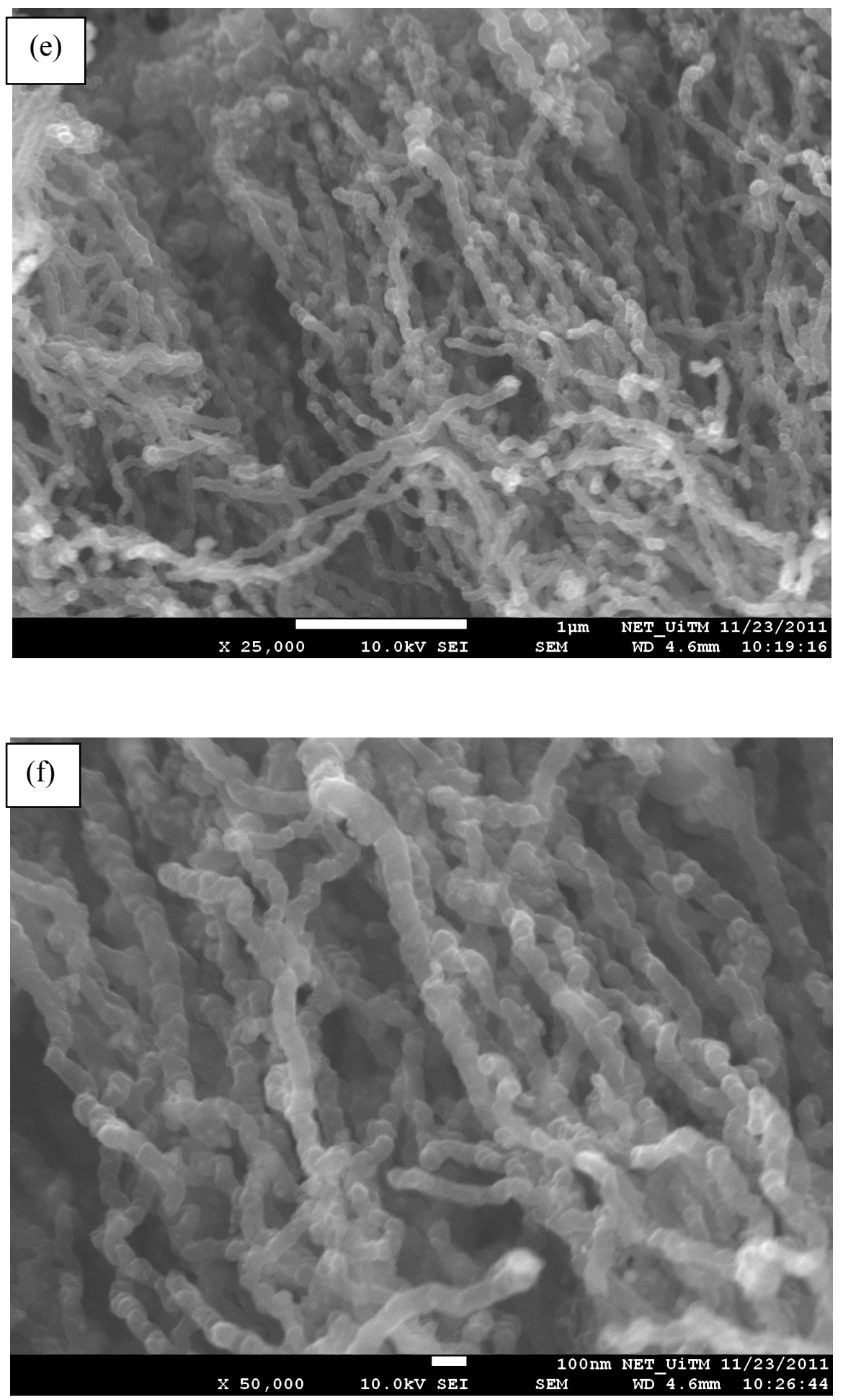
Nano Hybrids Vol. 2
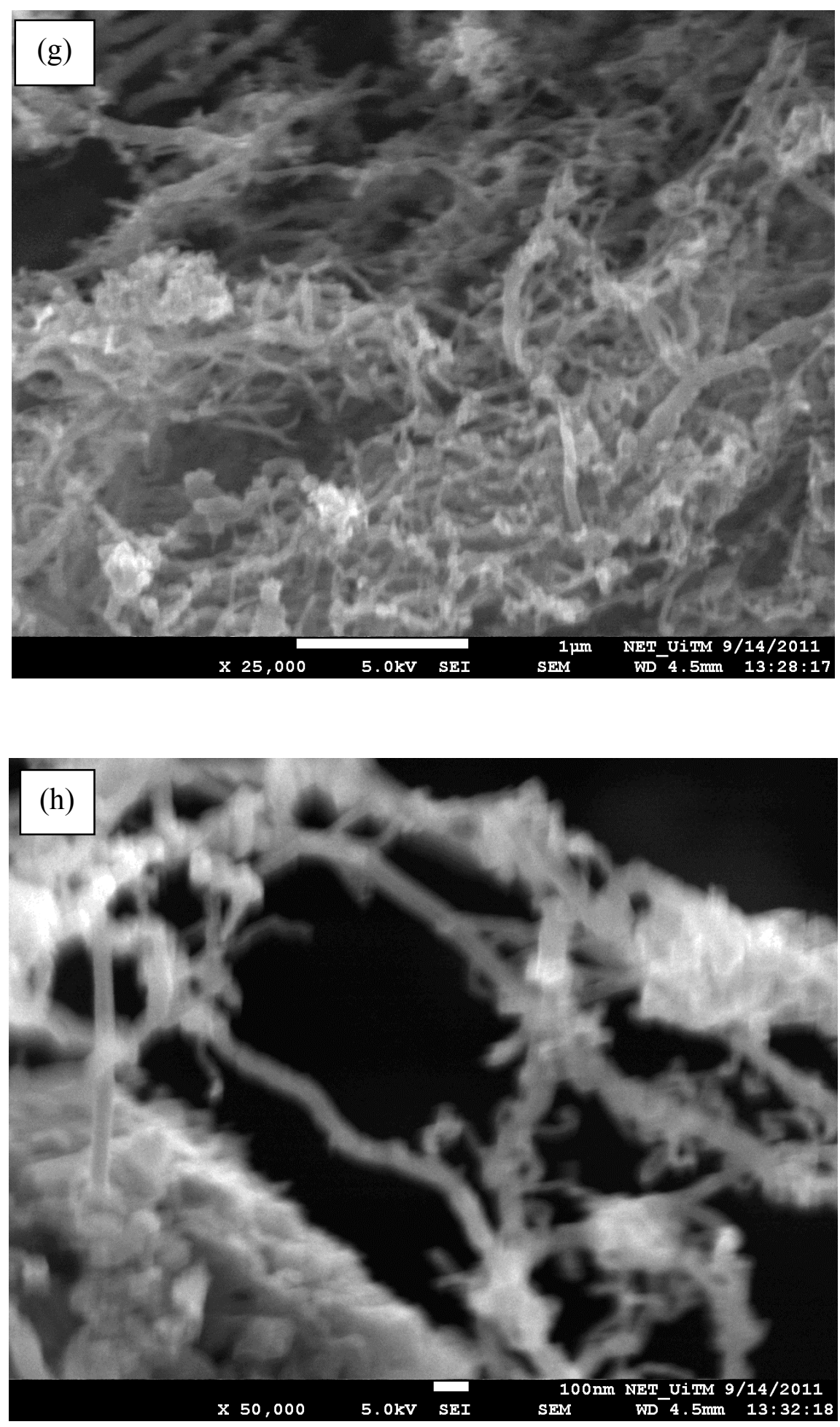

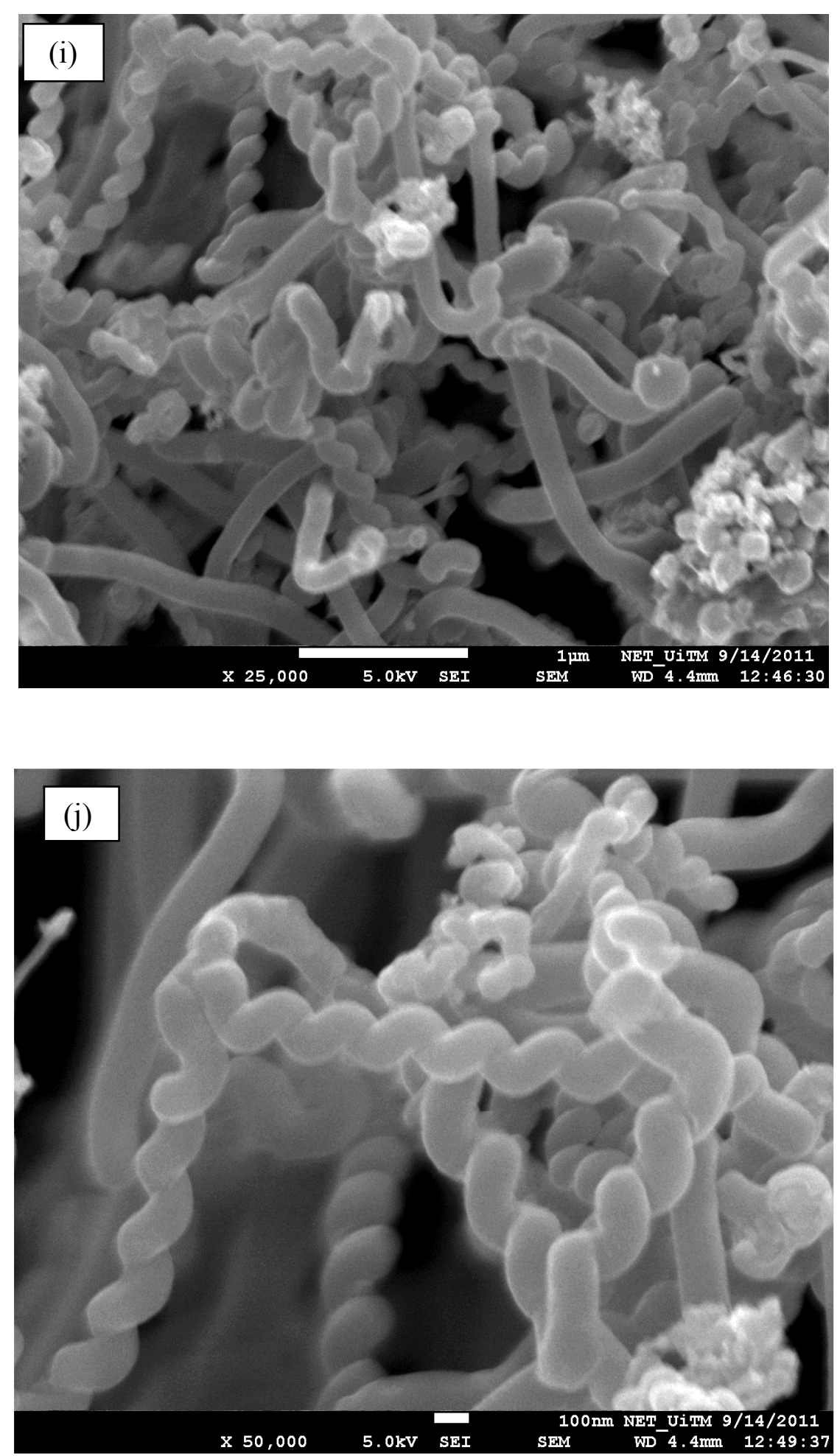

Fig. 2. FESEM images of CNT synthesized from different bio-hydrocarbon precursors: (a)-(b) palm, (c)-(d) olive, (e)-(f) coconut, (g)-(h) corn and (i)-(j) sesame oils.

The possible explanation for different surface morphology and diameter of the CNT produced can be related to the oil density. Among these bio-hydrocarbon precursors, the sesame oil has the highest density of $0.934 \mathrm{gcm}^{-3}$ (Table 2). Oil with high density requires high synthesis temperature for better 
pyrolysis process [29]. Due to fixed synthesis temperature at $750^{\circ} \mathrm{C}$ the higher density precursor may not completely pyrolyse, making the decomposition of the hydrocarbon vapor on the catalyst surface did not perform well. As a result, the tubes seemed to be low in quality, bigger in diameter and obviously blended with a-C and carbon particles. At the same time, from the highest mass which was loaded into the furnace by sesame oil, it was expected that higher carbon atoms were present during the synthesis process. This led to bigger CNT diameter as extra carbon atom may accumulate to form more walls on the CNT.

Table 2. Density and mass of bio-hydrocarbon precursors.

\begin{tabular}{|c|c|c|}
\hline Oil & Density $\left(\mathrm{gcm}^{-3}\right)$ & Mass (g) for $\mathbf{6} \mathbf{~ m l ~ m i x t u r e ~}$ \\
\hline Sesame & 0.934 & 5.60 \\
\hline Corn & 0.925 & 5.55 \\
\hline Coconut & 0.925 & 5.55 \\
\hline Olive & 0.918 & 5.51 \\
\hline Palm & 0.890 & 5.34 \\
\hline
\end{tabular}




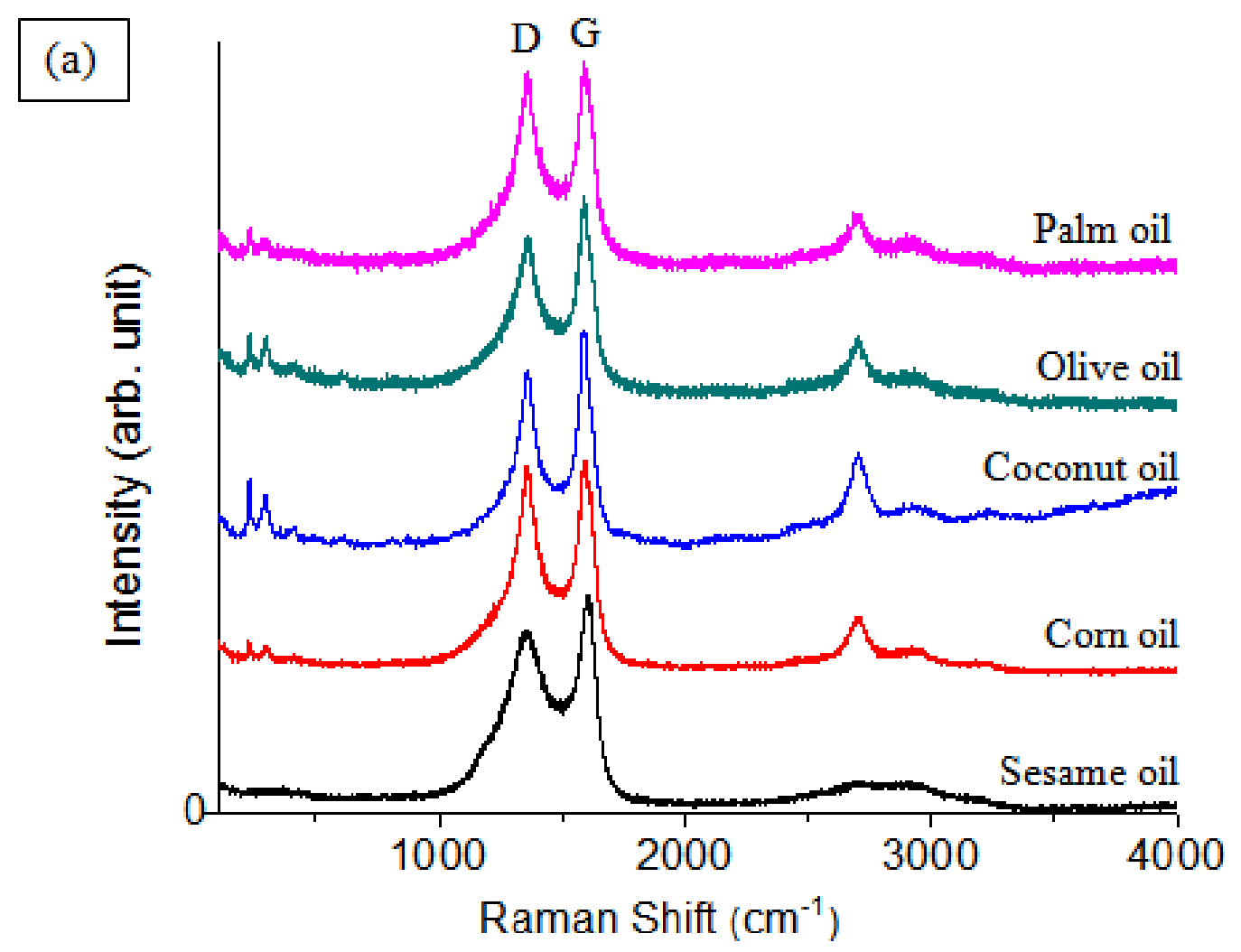

(b)

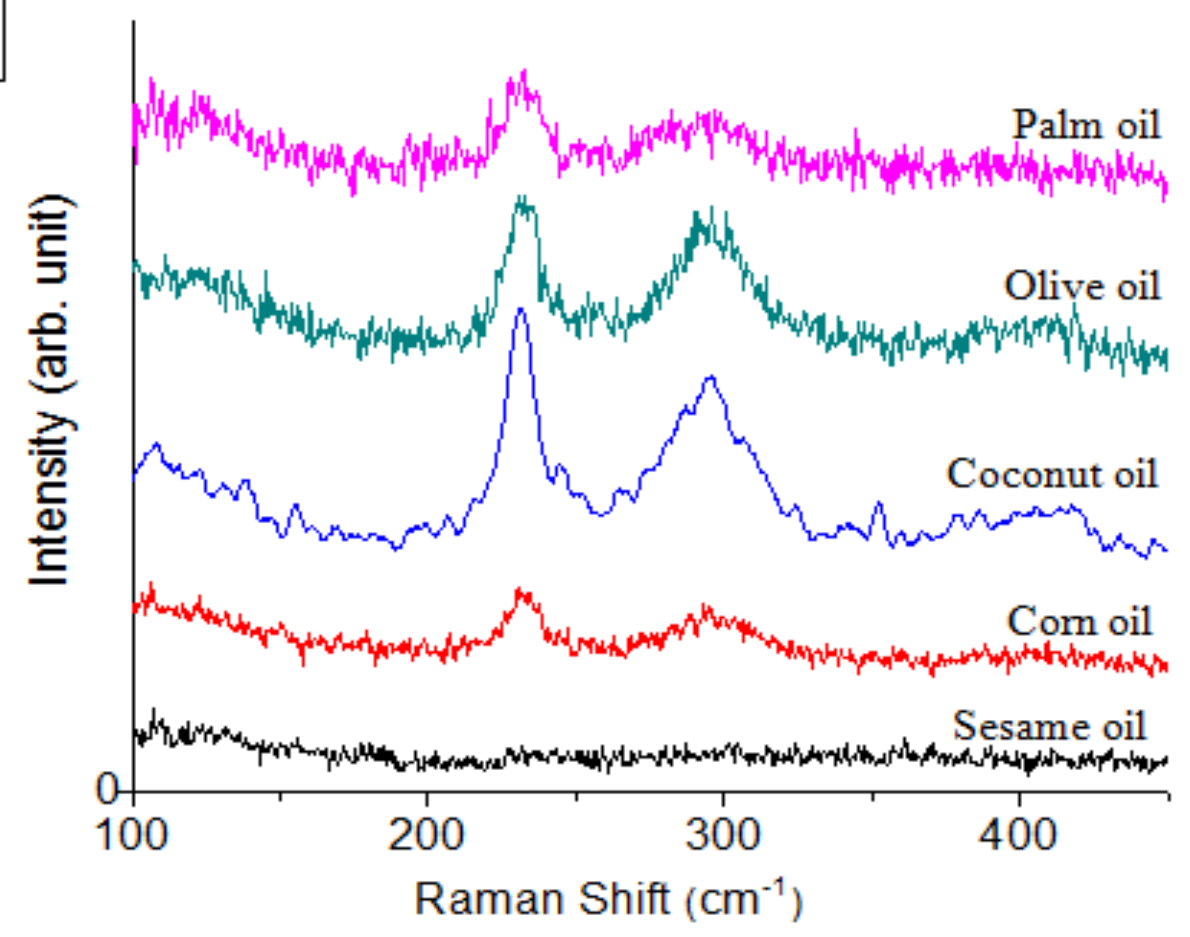




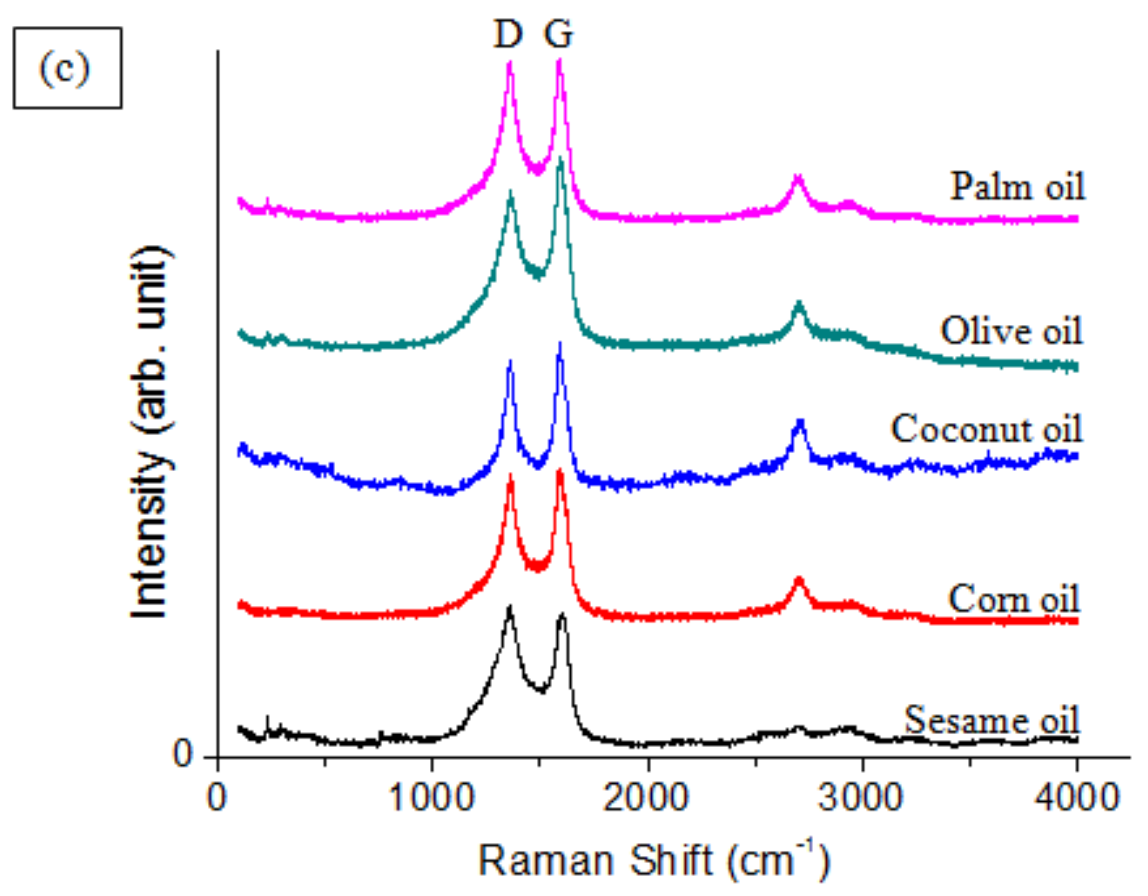

Fig. 3. (a) Typical Raman spectra of CNT from bio-hydrocarbon precursors, (b) Radial Breathing Modes (RBM) peaks appeared at below $500 \mathrm{~cm}^{-1}$ frequency range and (c) Typical Raman spectra of CNT reproduction from bio-hydrocarbon precursors.

Raman spectra of CNT synthesized with different precursors are shown on Fig. 3 (a). Two major peaks; the G-peak (1591.1-1603.9 $\mathrm{cm}^{-1}$ ) for the graphite crystallinity and the D-peak for the graphite disorder (1359.0-1365.4 $\left.\mathrm{cm}^{-1}\right)$ were observed in all samples. The integrated intensity ratio of the D and G peaks was used as a parameter to evaluate the crystallinity of $C N T$. The lower $\mathrm{I}_{\mathrm{D}} / \mathrm{I}_{\mathrm{G}}$ ratio corresponds for better quality tubes [30]. In this case, the CNT synthesized from coconut oil precursor showed the lowest $\mathrm{I}_{\mathrm{D}} / \mathrm{I}_{\mathrm{G}}$ ratio $(0.67)$ whereas the highest $\mathrm{I}_{\mathrm{D}} / \mathrm{I}_{\mathrm{G}}$ ratio was obtained from sesame oil-CNT sample (0.87). The higher value of $\mathrm{I}_{\mathrm{D}} / \mathrm{I}_{\mathrm{G}}$ ratio may be due to the presence of defect such as a-C, other carbon particles and low graphitization of the nanotube. The $\mathrm{I}_{\mathrm{D}} / \mathrm{I}_{\mathrm{G}}$ values were found to be 0.81 for corn, 0.72 for olive and 0.81 for palm oil. From the previous reports, the $\mathrm{I}_{\mathrm{D}} / \mathrm{I}_{\mathrm{G}}$ ratio for CNT synthesized from palm and coconut oil were around 0.52 [17] and 1.39 [23] respectively. This show that the CNT synthesized from coconut oil has a better crystallinity as demonstrated by lower $\mathrm{I}_{\mathrm{D}} / \mathrm{I}_{\mathrm{G}}$ ratio. However, a slight increase in $\mathrm{I}_{\mathrm{D}} / \mathrm{I}_{\mathrm{G}}$ ratio for palm oil-CNT sample demonstrated a deterioration of CNT crystallinity produced in the current study. 
Nonetheless, it was interesting to note that the frequency radial breathing mode (RBM) peaks were detected for the CNT samples synthesized using palm, olive, coconut and corn oils, indicating the presence of single-walled CNT (SWCNT) in the samples (Fig. 3 (b)). However, the RBM peak intensity varies with oils precursor. The significant RBM peaks were detected for the CNT prepared from coconut oil, whereas faint peaks were detected for the CNT synthesized using corn oil. Fig. 3(b) shows two RBM peaks identified at 232.3 and 295.4 for CNT samples synthesized from biohydrocarbon precursors. This corresponds to the tube diameters of 1.07 and $0.84 \mathrm{~nm}$ (calculated from [31]). For accuracy and reliability of data, the CNT for every precursor were reproduced for several times. The important point of interest was that it consistently shows that the sample prepared using coconut oil demonstrated the lowest $\mathrm{I}_{\mathrm{D}} / \mathrm{I}_{\mathrm{G}}$ ratio $(0.75)$ as compared to other samples. These were followed by CNT produced by olive $\left(\mathrm{I}_{\mathrm{D}} / \mathrm{I}_{\mathrm{G}}\right.$ ratio $\left.\sim 0.76\right)$, palm $\left(\mathrm{I}_{\mathrm{D}} / \mathrm{I}_{\mathrm{G}}\right.$ ratio $\left.\sim 0.82\right)$, corn $\left(\mathrm{I}_{\mathrm{D}} / \mathrm{I}_{\mathrm{G}}\right.$ ratio $\sim 0.83)$ and sesame $\left(\mathrm{I}_{\mathrm{D}} / \mathrm{I}_{\mathrm{G}}\right.$ ratio $\left.\sim 0.92\right)$ oils. Fig. 3 (c) shows the typical micro-Raman spectra for the reproduction of CNT synthesized from bio-hydrocarbon precursors. 
Table 3. Raman and RBM peak position, G \& D intensity ratios and SWCNT diameter for biohydrocarbon precursors.

\begin{tabular}{|c|c|c|c|c|c|c|c|}
\hline Samples & $\begin{array}{c}\text { G-peak } \\
\left(\mathrm{cm}^{-1}\right)\end{array}$ & $\begin{array}{c}\text { G-width } \\
\left(\mathrm{cm}^{-1}\right)\end{array}$ & $\begin{array}{c}\text { D-peak } \\
\left(\mathrm{cm}^{-1}\right)\end{array}$ & $\begin{array}{c}\text { D-width } \\
\left(\mathrm{cm}^{-1}\right)\end{array}$ & $\begin{array}{l}\mathbf{I}_{\mathbf{D}} / \mathbf{I}_{\mathbf{G}} \\
\text { ratio }\end{array}$ & $\begin{array}{l}\text { RBM } \\
\text { peaks } \\
\left(\mathrm{cm}^{-1}\right)\end{array}$ & $\begin{array}{c}\text { SWCNT } \\
\text { diameter (nm) } \\
\text { (calculated } \\
\text { from d } \mathrm{d}_{\mathrm{t}}=248 \\
\left(\mathrm{~cm}^{-1} \mathrm{~nm}\right) / \\
\omega_{\mathrm{RBM}} \\
\left(\mathrm{cm}^{-1}\right)\end{array}$ \\
\hline $\begin{array}{c}\text { Sesame } \\
\text { oil }\end{array}$ & 1603.9 & 75.3 & 1365.4 & 245.5 & 0.87 & - & - \\
\hline Corn oil & 1595.5 & 78.0 & 1360.6 & 183.5 & 0.81 & $\begin{array}{l}232.3, \\
295.4\end{array}$ & $1.07,0.84$ \\
\hline $\begin{array}{l}\text { Coconut } \\
\text { oil }\end{array}$ & 1591.1 & 63.8 & 1360.7 & 123.9 & 0.67 & $\begin{array}{l}232.1 \\
294.2\end{array}$ & $1.07,0.84$ \\
\hline Olive oil & 1594.4 & 72.9 & 1359.0 & 202.3 & 0.72 & $\begin{array}{l}232.2, \\
295.6\end{array}$ & $1.07,0.84$ \\
\hline Palm oil & 1594.6 & 79.7 & 1361.5 & 183.6 & 0.81 & $\begin{array}{l}232.2, \\
297.4\end{array}$ & $1.07,0.84$ \\
\hline
\end{tabular}

Fig. 4 (a) and (b) shows the TGA and differential thermogravimetric (DTG) graphs for the asgrown CNT from bio-hydrocarbon precursors. It was found that a small amount of weight loss $(\sim 1.0 \%)$ at the temperature of 219.21 to $233.57{ }^{\circ} \mathrm{C}$ occurred mainly due to the presence of unreacted hydrocarbon in the CNT samples. The hydrocarbon content was not seen in the case of CNT prepared using olive and coconut oil precursors. In the temperature range of 400 to $550{ }^{\circ} \mathrm{C}$, a small weight loss was observed which was due to the decomposition of a-C that contributed around 3.76- 
$9.27 \%$ of the total weight. The decomposition of CNT started at around 603.17 to $935.51^{\circ} \mathrm{C}$ and approximately $17.36 \%$ of the sample remained after performing TGA analysis up to $1000{ }^{\circ} \mathrm{C}$. This residue was mainly due to the existence of Fe catalyst which was found in between or within the inner walls of the CNT $[32,33]$. There was no weight gain observed during TGA analysis, indicates no oxidation of the Fe particles took place. The weight gain due to oxidation occurred when the catalyst particles were exposed or adhered on the CNT surface. Hence, through this analysis it was suggested that the catalysts in this study were completely encapsulated within the tube wall. Based on the TGA results, it can be concluded that the highest CNT purity was detected in sample synthesized from coconut oil (81.95\%).

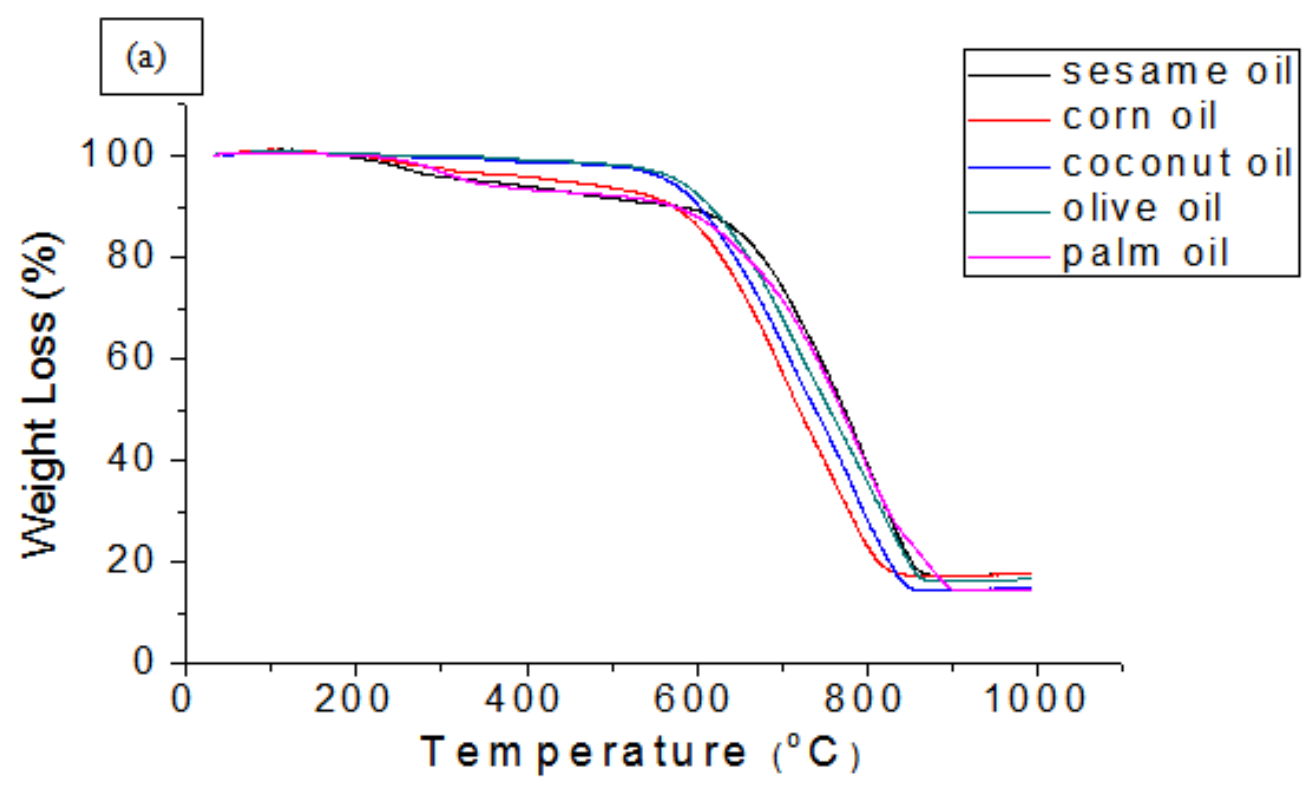




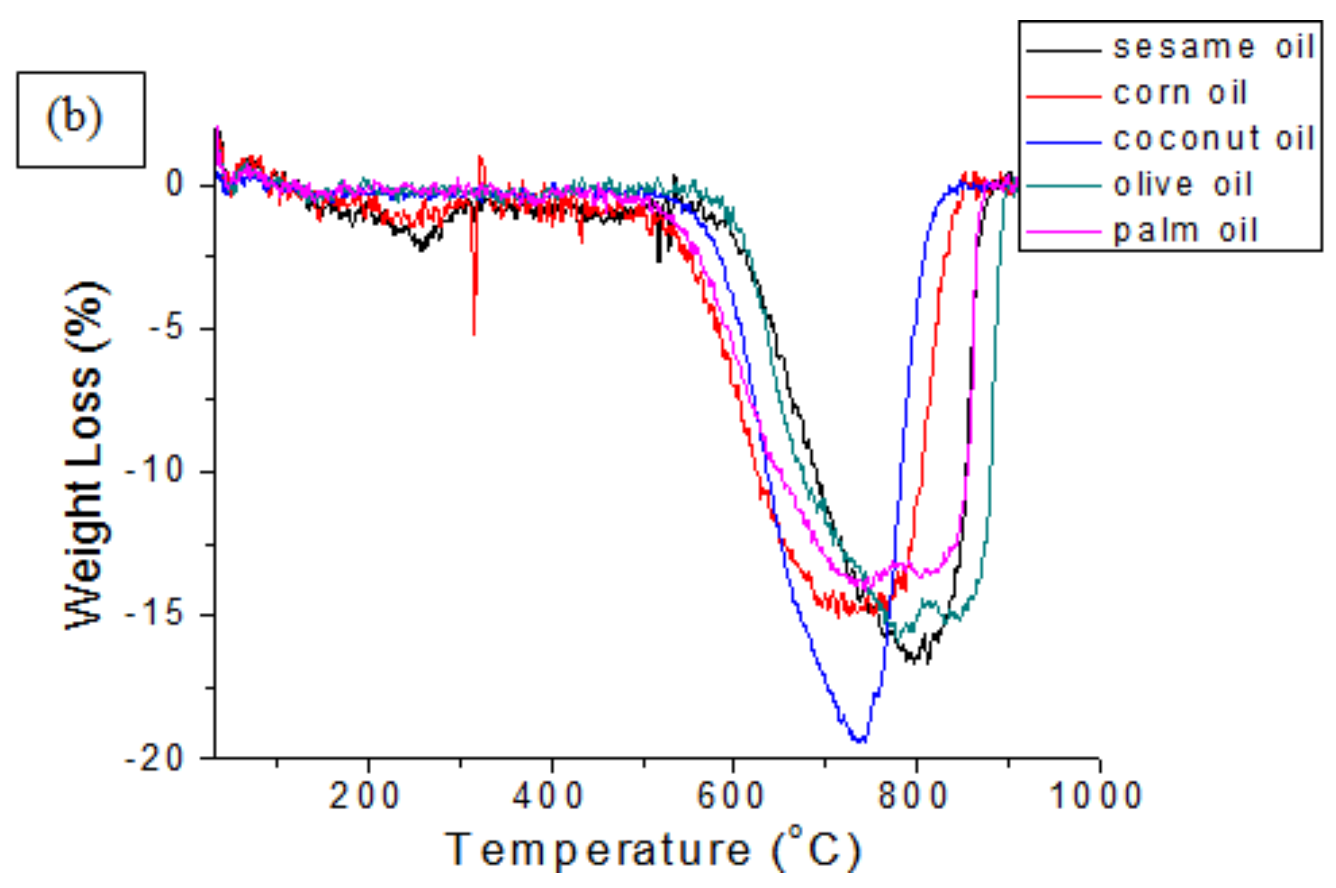

Fig. 4. (a) TGA and (b) DTG analysis of CNT synthesized using bio-hydrocarbon precursors.

The EDX spectrum in Fig. 5 (a)-(e) revealed that the CNT synthesized using bio-hydrocarbon precursors were highly composed of carbon content and a very small amount of Fe and oxygen. With this, it was evident that the samples contain Fe particles as depicted in TGA analysis.

(a)

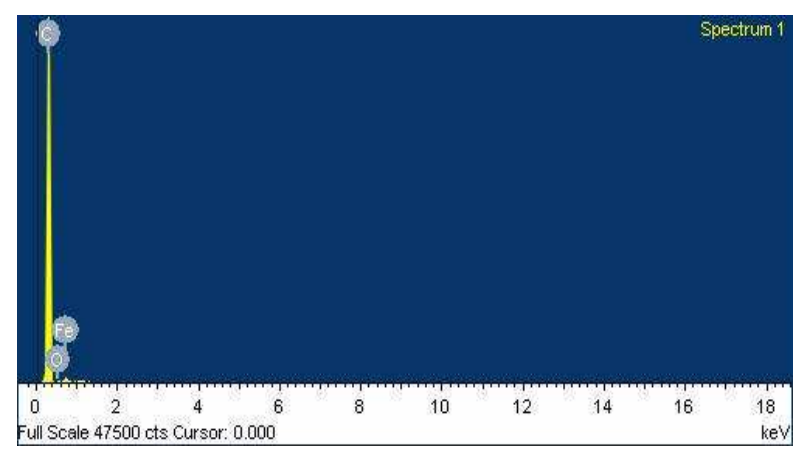

(b)

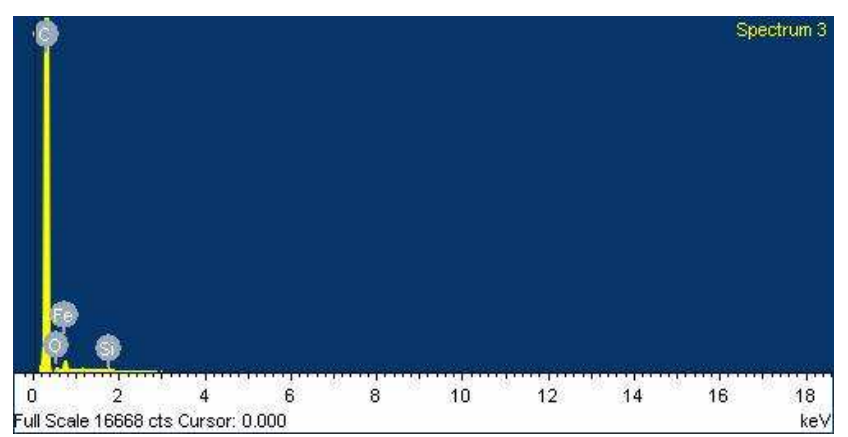


(c)

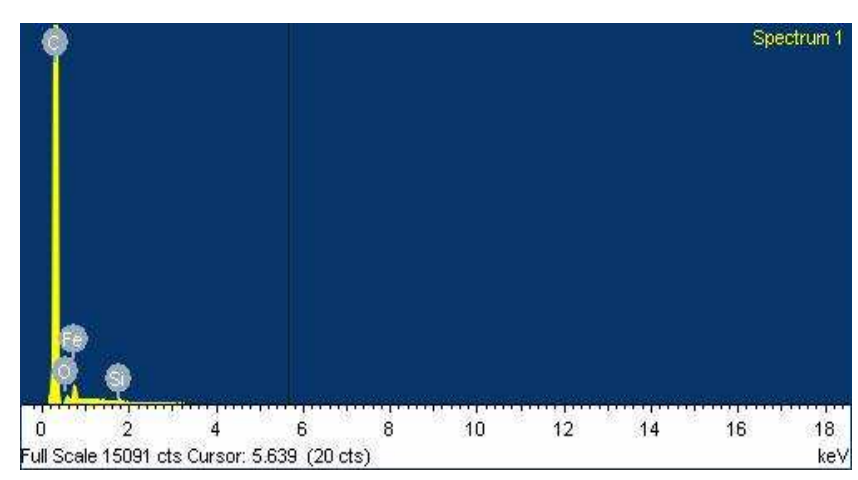

(d)

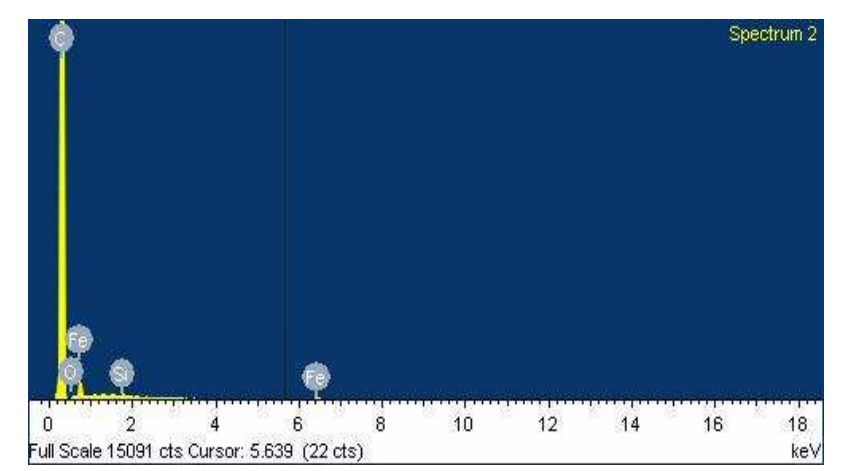

(e)

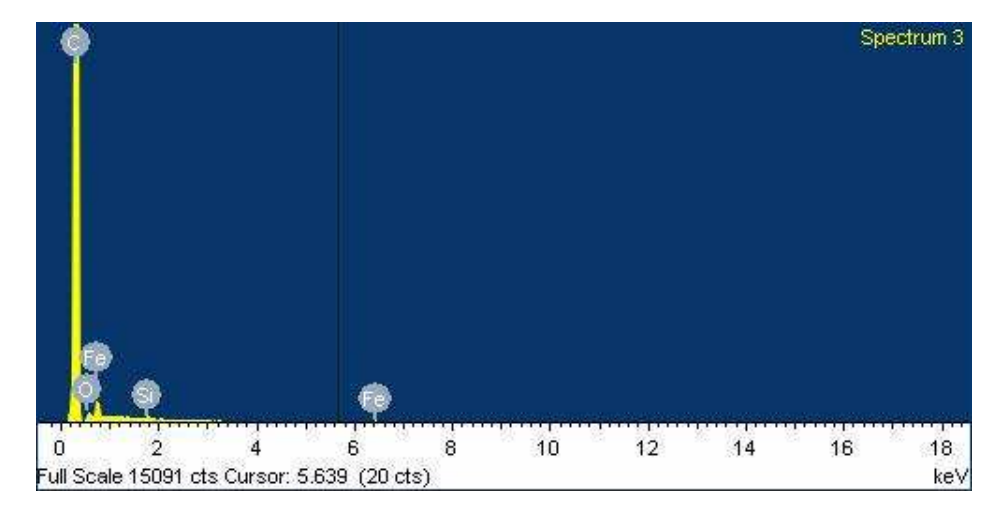

Fig. 5. EDX spectrum for CNT synthesized from: (a) palm, (b) olive, (c) coconut, (d) corn and (e) sesame oil.

\section{Conclusions}

To conclude, we have successfully prepared CNT using palm, coconut, olive, corn and sesame oils and the quality of CNT produced were comparable to the CNT prepared from conventional precursor. The CNT synthesized from coconut oil shows the best surface morphology and crystallinity deduced from lowest $\mathrm{I}_{\mathrm{D}} / \mathrm{I}_{\mathrm{G}}$ of 0.67 . The sample also demonstrated the highest purity of $81.95 \%$. The presence of Fe particles in the nanotubes was evidenced by EDX spectrum and TGA analysis. In terms of diameter, the sample with smallest diameter was detected in palm oil-CNT sample. The difference in precursor's density may be the factor attributed to different morphology and diameter obtained. By controlling the synthesis parameter particularly synthesis temperature it will possibly increase the quality and purity of the CNT produced. 


\section{Acknowledgements}

The authors are grateful to the Fundamental Research Grant Scheme (FRGS) (Grant code: 20100064-102-02), Department of Physics, Universiti Pendidikan Sultan Idris and Universiti Teknologi Mara, Shah Alam for financial and facilities support of this work.

\section{References}

[1] J. Robertson, Realistic applications of CNTs, Mater. Today 7 (2004) 46-52.

[2] N.F.A. Zainal, A.A. Azira, S.F. Nik, M. Rusop, The electrical and optical properties of PMMA/MWCNTs nanocomposite thin films, Nanocomposite Thin Films (2009) 750-754.

[3] R.H. Baughman, A.A. Zakhidov, W.A. de Heer, Carbon nanotubes the route toward applications, Science 297 (2002) 787-792.

[4] Q.H. Wang, T.D. Corrigan, J.Y. Dai, R.P.H. Chang, A.R. Krauss, Field emission from nanotube bundle emitters at low fields, Appl. Phys. Lett. 70 (1997) 3308-3310.

[5] K. Liu, W.W., Z. Xu, X. Bai, E. Wang, Y. Yao, J. Zhang, L. Zheng, Chirality-dependent transport properties of double-walled nanotubes measured in situ on their field-effect transistors, J. Am. Chem. Soc. 131 (2009) 62.

[6] M. Cadek, R. Murphy, B. McCarthy, A. Drury, B. Lahr, R.C. Barklie, M. Panhuis, J.N. Coleman, W.J. Blau, Optimisation of the arc-discharge production of multi-walled carbon nanotubes, Carbon 40 (2002) 923-928.

[7] A.V. Rode, E.G. Gamaly, A.G. Christy, J. Fitz Gerald, S.T. Hyde, R.G. Elliman, B. LutherDavies, A.I. Veinger, J. Androulakis, J. Giapintzakis, Strong paramagnetism and possible ferromagnetism in pure carbon nanofoam produced by laser ablation, J. Magn. Magn. Mater. 290-291 (2005) 298-301.

[8] A.B. Suriani, M. Salina, M.S.P. Sarah, R.M. Nor, A. Anuar, Y.M. Siran, S.A.M. Rejab, A.J. Asis, S. Tahiruddin, S. Abdullah, M. Rusop, Effect of temperature on the growth of vertically aligned carbon nanotubes from palm oil, Defect and Diffusion Forum 312-315 (2011) 900-905. 
[9] A.B. Suriani, M. Salina, M.S.P. Sarah, S.A.M. Zobir, R.M. Nor, A. Anuar, Y.M. Siran, S.A.M. Rejab, A.J. Asis, S. Tahiruddin, S. Abdullah, M. Rusop, The effect of precursor vaporization temperature on the growth of vertically aligned carbon nanotubes using palm oil, Defect and Diffusion Forum 312-315 (2011) 906-911.

[10] M. Kumar, Y. Ando, Controlling the diameter distribution of carbon nanotubes grown from camphor on a zeolite support, Carbon 43 (2005) 533-540.

[11] M. Kumar, Y. Ando, Single-wall and multi-wall carbon nanotubes from camphor botanical hydrocarbon, Diamond Relat. Mater. 12 (2003) 1845-1850.

[12] R.A Afre, T. Soga, T. Jimbo, M. Kumar, Y. Ando, M. Sharon, P.R. Somani, M. Umeno, Carbon nanotubes by spray pyrolysis of turpentine oil at different temperatures and their studies, Microporous Mesoporous Mater. 96 (2006) 184-190.

[13] P. Ghosh, T. Soga, R.A. Afre, T. Jimbo, Simplified synthesis of single-walled carbon nanotubes from a botanical hydrocarbon: Turpentine oil, J. Alloys Compd. 462 (2008) 289-293.

[14] K. Awasthi, R. Kumar, R.S. Tiwari, O.N. Srivastava, Large scale synthesis of bundles of aligned carbon nanotubes using a natural precursor: turpentine oil, J. of Experimental Nanoscience 5 (2010) 498-508.

[15] P. Ghosh, R.A. Afre, T. Soga, T. Jimbo, A simple method of producing single-walled carbon nanotubes from a natural precursor: Eucalyptus oil, Mater. Letters 61 (2007) 37683770 .

[16] A.B. Suriani, M. Salina, M.S. Puteri Sarah, M.Z. Syazwan Afif, M.N. Roslan, M.S. Yosri, M.R. Syahril Anuar, J.A. Ahmad, T. Shawaluddin, S. Abdullah, M. Rusop, The effect of precursor vaporization temperature on the growth of vertically aligned carbon nanotubes using palm oil.Defect and Diffusion, ISI/SCOPUS Cited Publication 312-315(2011) 906911.

[17] A.B. Suriani, A.A. Azira, S.F. Nik, R.M. Nor, M. Rusop, Synthesis of vertically aligned carbon nanotubes using natural palm oil as carbon precursor, Mater. Letters 63 (2009) 2704-2706. 
[18] A.B. Suriani, F. Mohamad, A.A. Azira, N. Hajar, M.H. Mamat, M.S.P. Sarah, M.Z. Musa, R.M. Nor, M. Rusop, Effect of catalyst concentration on the growth of palm oil based vertically aligned carbon nanotubes, AIP Conference Proceedings 1250 (2011) 369-372.

[19] M.S. Azmina, A.B Suriani, A.N. Falina, M. Salina, M. Rusop, Temperature effects on the production of carbon nanotubes from palm oil by thermal vapor deposition method, Advanced Materials Research 364 (2012) 359-362.

[20] A.B. Suriani, R.M. Nor, M. Rusop, Vertically aligned carbon nanotubes synthesized from waste cooking palm oil, Journal of the Ceramics Society of Japan 118 (2010) 963-968.

[21] R. Kumar, S.T. Radhey, N.S. Onkar, Scalable synthesis of aligned carbon nanotubes bundles using green natural precursor: neem oil, Nanoscale Research Letters 6 (2011) 92.

[22] K. Awasthi, R. Kumar, H. Raghubanshi, S. Awasthi, R. Pandey, D. Singh, T.P. Yadav, O.N. Srivastava, Synthesis of nano-carbon (nanotubes, nanofiber, graphene) materials, Bull. Mater. Sci. 34 (2011) 607-614

[23] S. Paul, S.K. Samdarshi, A green precursor for carbon nanotube synthesis, New Carbon Materials 26 (2011) 85-88.

[24] M.S. Azmina, A.B. Suriani, A.N. Falina, M. Salina, J. Rosly, M. Rusop, Preparation of palm oil based carbon nanotubes at various ferrocene concentration, Advance Materials Research 364 (2012) 408-411.

[25] S. Maghsoodi, Z. Gholami, H. Chourchian, Y. Mortazavi, A.A. Khodadadi, A novel biosensor using entangled carbon nanotubes layer grown on an alumina substrate by CCVD of methane on $\mathrm{FeO}_{\mathrm{x}}-\mathrm{MgO}_{\mathrm{x}}$, Sensors Actuat. B-Chem. 141 (2009) 526-531.

[26] B. Bahrami, A. Khodadadi, Y. Mortazavi, M. Esmaieli, Short time synthesis of high quality carbon nanotubes with high rates by CVD of methane on continuously emerged iron nanoparticles, Appl. Surf. Sci. 257 (2011) 9710-9716.

[27] C.M. Seah, S.P. Chai, A.R. Mohamed, Synthesis of aligned carbon nanotubes, Carbon 49 (2011) 4613-4635.

[28] Z.F. Ren, Z.P. Huang, J.W. Xu, J.H. Wang, P. Bush, M.P. Siegal, P.N. Provencio, Synthesis of large arrays of well-aligned carbon nanotubes on glass, Science 282 (1998) 1105-1107. 
[29] P.T. Williams, E.A. Williams, Fluidised bed pyrolysis of low density polyethylene to produce petrochemical feedstock, J. Anal. Appl. Pyrol. 51 (1999) 107-126.

[30] S. Zhu, H. Zhang, R. Bai, Microwave-accelerated dissolution of MWNT in aniline, Mater. Lett. 61 (2007) 16-18.

[31] M.S. Dresselhaus, G. Dresselhaus, R. Saito, A. Jorio, Raman spectroscopy of carbon nanotubes, Phys. Rep. 10 (2004) 1016.

[32] D. Bom, R. Andrews, D. Jacques, J. Anthony, B. Chen, M.S. Meier, J.P. Selegue, Thermogravimetric analysis of the oxidation of multiwalled carbon nanotubes: evidence for the role of defect sites in carbon nanotube chemistry, Nano Letters 2 (2002) 615-619.

[33] C. M. Chen, M. Chen, F.C. Leu, S.Y. Hsu, S.C. Wang, S.C. Shi, C.F. Chen, Purification of multi-walled carbon nanotubes by microwave digestion method, Diamond Relat. Mater. 13 (2004) 1182-1186. 